\title{
Lifelong Education in Business: Role of Simulation Games in the Teaching Process
}

\section{Ph.D. Sevar Mammadova}

Azerbaijan State University of Economics (UNEC)

UNEC Business School

Department of "Economics and business administration"

sevar_mammadova@unec.edu.az

Article History: Received: 10 November 2020; Revised 12 January 2021 Accepted: 27 January 2021; Published online: 5 April 2021

\begin{abstract}
The significance of business simulation games (BSG) rapidly increases. And this quite understandable. Because simulation games are based on the model playback mode realistic processes, events, locations or situations. The necessity of BSG in the educational process can be explained on the one hand by the growing demand of the labor market in specialists with practical skills, and on the other hand by growing needs of students to be able to navigate themselves through unfamiliar situations and find their decision in a proper and responsible way, instead of blind copying teachers instructions. BSG offers a broad scope of the forms of competencies students such as an ability to work in group teamwork, find a common language and understand that is globally relevant and informed while providing space to adapt the framework to local contexts.

Business simulation games train students create risk-free spaces where everyone can work out specific skills and feel the effects of own decision-making, requiring a certain level of risk.

Entrepreneurial activity is pivotal to the continued dynamism of the private sector, as the generation of new businesses fosters competition and economic growth. This is particularly relevant for Azerbaijan, whose entrepreneurship and business innovation levels are low, and it faces a central challenge to create conditions that will facilitate growth in nonoil tradable sectors. Therefore the proposed paper has three objectives: development of teaching resources and tools for delivery of entrepreneurship education. BSG will facilitate strategic problemsolving in life-like simulated business environments and it will be attached to the existing UNEC incubator. BSG should become an integral part of the educational process. Simulation games allow students to practice and improve their entrepreneurial skills in a 'virtual' environment by making informed decisions and applying the knowledge and skills acquired in the class.

According to OECD LEARNING COMPASS 2030, the educational process should be focused on evolving learning framework that sets out an aspirational vision for the future of education. The wider goals of education open new horizons of orientation towards the tomorrow we want to see. Thinking globally acting locally we will create collective well-being for every society's member.
\end{abstract}

Keywords: simulation games, entrepreneurial activity, virtual environment

\section{Introduction}

In 1991 after the collapse of the USSR Azerbaijan restored state independence and became the country in transition that has inherited an inefficiently functioning system of a planned economy. Inherited Soviet high education service also fell into disrepair. Even though Soviet education had positive sides, such as free education, the strong reputation of exact sciences, high-quality technical education, motivating factor of enlightening, this system also had its flaws. The most and the worse one was the fact that the key place in the higher education system was occupied by theoretical knowledge instead of a practical one. Besides, there was a very low demand for learning foreign languages, software development and programming languages, which became a barrier to integration into 
the global education system. With the collapse of the planned economy, the country began a transitional crisis, which of course has also affected the activities of higher education institutions.

New reforms in the education system of Azerbaijan began since the early 1990s. However, there were difficulties associated with the lack of a legal framework for education. There was no law on education, baccalaureate, and magistracy, the credit system was also absent. Digital teaching staff skills were extremely poorly developed. Even though Internet media appeared in Azerbaijan in 1996, there was no digitalization policy in the country, teachers did not know even how to use a computer. It took a long time and was quite difficult to penetrate people's mind, explain them the role and essence of e-learning and digital possibilities on the way of quick and easy search of needed materials.

In the context of globalization, one of the main tasks of the educational system in Azerbaijan was to integrate into the European educational system, along with the creation of a competitive educational system capable to meet the needs of the global labor market. This task became even more urgent when in 2001 Azerbaijan became a member of the Council of Europe. The integration of the national education system and implementation of European education standards have become the main and priority goal of the newly obtained a sovereignty Azerbaijan.

To achieve this goal, it was necessary to create national educational standards, determine the possibilities and advantages of the Bologna credit system and its appliance in Azerbaijan.

In 1999, after the approval of the main educational reforms, comprehensive changes began in the entire educational system of Azerbaijan. In 2005, an official document on the inclusion of Azerbaijan into the Bologna system was signed. The theoretical and legal basis of the process was set out in the document "The Structure of Minimum State Requirements for the Level and Content of Bachelor's Degree adopted in 2006". By joining the Bologna system, Azerbaijan automatically assumed obligations to further improvement of education quality, as well as to adapt its educational system to the advanced educational systems of European countries and accepted several other commitments to deal with. The country for sure faced a need for fundamental reforms in higher education. Structural changes were made to the higher education system, new specialties and subjects in computer science were added to the curricula. However, the transition to a new system did not solve all the problems associated with higher education in Azerbaijan.

The usage problems of digital technology still exist in the education system. Since the ICT industry is constantly developing, computer knowledge must constantly be improved too. Azerbaijan State University of Economics (UNEC) like other universities of higher education often have a lack of advanced experience, qualified specialists in the field of digital technology.

Creating a digital environment at UNEC require an appropriate digital concept, the training of specialists, who will use modern digital technologies and then provide training for trainers, transfer new knowledge students and thus develop a great value for a new generation.

Effective education at business schools should be oriented on designing of simulation games that will be very useful and requested from the labor market. To be able to meet the main requirements of the business world each institution has to look for suitable methods to providing not only theoretical basis but also mainly practical skills and should guide students to creative, logical and innovative thinking. Designed for a business student's Business simulation games (BSG) is an effective educational tool today because games allow you to simulate various economic occasions and conditions in the market and motivate students to personal decision-making.

BSG are active didactic tools used in teaching Economics, Marketing, Management, HR, Procurement and other disciplines and considered learning methods designed on empirical learning. They encourage students to obtain new knowledge and skills through experience. Playing on BSG, students may check and forecast the short-and long-term impact of economic indicators on the business, and then check and correct their decisions if needed.

This paper aims to emphasize the importance and efficiency of business games in the modern learning process. The BSG invites students to be innovators even virtually because they will see opportunities for local developments, use engineering achievements to design new products/services. Student investigations such as surveys, different forms of collaboration, interviews can be very interesting for local entrepreneurs. Method Experiential and Action Learning Pedagogies, Case Method Teaching, Design-thinking, problem-based learning.

\section{Theoretical view}

The BSG have been widely used in most universities since the second half of the 20th century. The use of BSG at business schools as a learning tool becomes very popular nowadays. According to Faria about $95 \%$ of the all business schools united within the framework of the American Association to Advance Collegiate Schools of 
Business known as AACSB International included simulation games in their curriculums. The leading universities of the USA, Canada, France, Great Britain, Australia, New Zealand, Turkey, the United Arab Emirates, China, Singapore, Taiwan, South Korea, India, and Lebanon are members of this association. Is this the secret of the successful adaptation of companies in these countries to the changing global business environment? As we can see, none of the CIS countries are members of this association. Is this the reason for lagging behind the trends of the world market?

In most cases, new businesses fail. But most of those failures are preventable. And we consider that learning students by playing simulation games in a virtual competitive environment can orient and focus them to think comprehensively and practically, weigh the pros and cons before making a decision.

Development of ICT and computer sciences has created a wide platform for holding practical lessons using digital business games. Simulation games can incorporate various management-related disciplines such as marketing, accounting, HR, corporate social responsibility, procurement, entrepreneurship, logistics, and others.

Thinking and acting entrepreneurially can and should be taught in classrooms.

\subsection{Learning process}

The simulation is digitally based and doesn't need to install a special application and can be generally recognized from the existing computer that that has access to the Internet. The simulation base encourages team participants to work collectively. Each member of the group is given an account that allows them to make decisions create various situations on their own. To be able to make the right decision all results should be combined with findings of other teams. The web-designed platform should obligatory include web-forum to communicate with every team in the on-line market. Business simulation games train students and managers create risk-free spaces where everyone can work out specific skills and feel the effects of own decision-making, requiring a certain level of risk. The main characteristics we can give as followings:

- Reality

- Risk control

- Skills training (practice new behavior)

- Feeling and understanding the consequences of their own decisions.

We can imagine the learning process as given on the fig. 1 .

Students will be given a basic set of learning materials and tasks and a fixed time to create and design their decisions. To be able to manage virtually a fully integrated company and start a business student will be given the conditional seed capital. The whole class will be divided into teams and every team will have a chance to earn money in a virtual environment. In the process of BSG, they can hire and dismiss from work employees, open affiliated offices and then close them if it is necessary.

For a brief demo of the strategy and business policy simulation, please go to https://www.marketplacesimulation.com/strategy-business-policy-demo

A brief demo of the BSG can be observed at the https://www.marketplace-simulation.com/strategy-business-policy-demo A teacher of strategic management has to use a combination of methods like lectures, videos and case studies to impart learning. Learning through case studies is better than listening to lectures or videos. The role of the decision-makers allows students to think pragmatically and practically and this is undoubtedly the most effective tool for learning. The scope of interesting issues 
may touch such questions as what strategies can be used to occupy market niches? what changed? what was lost? And etc.

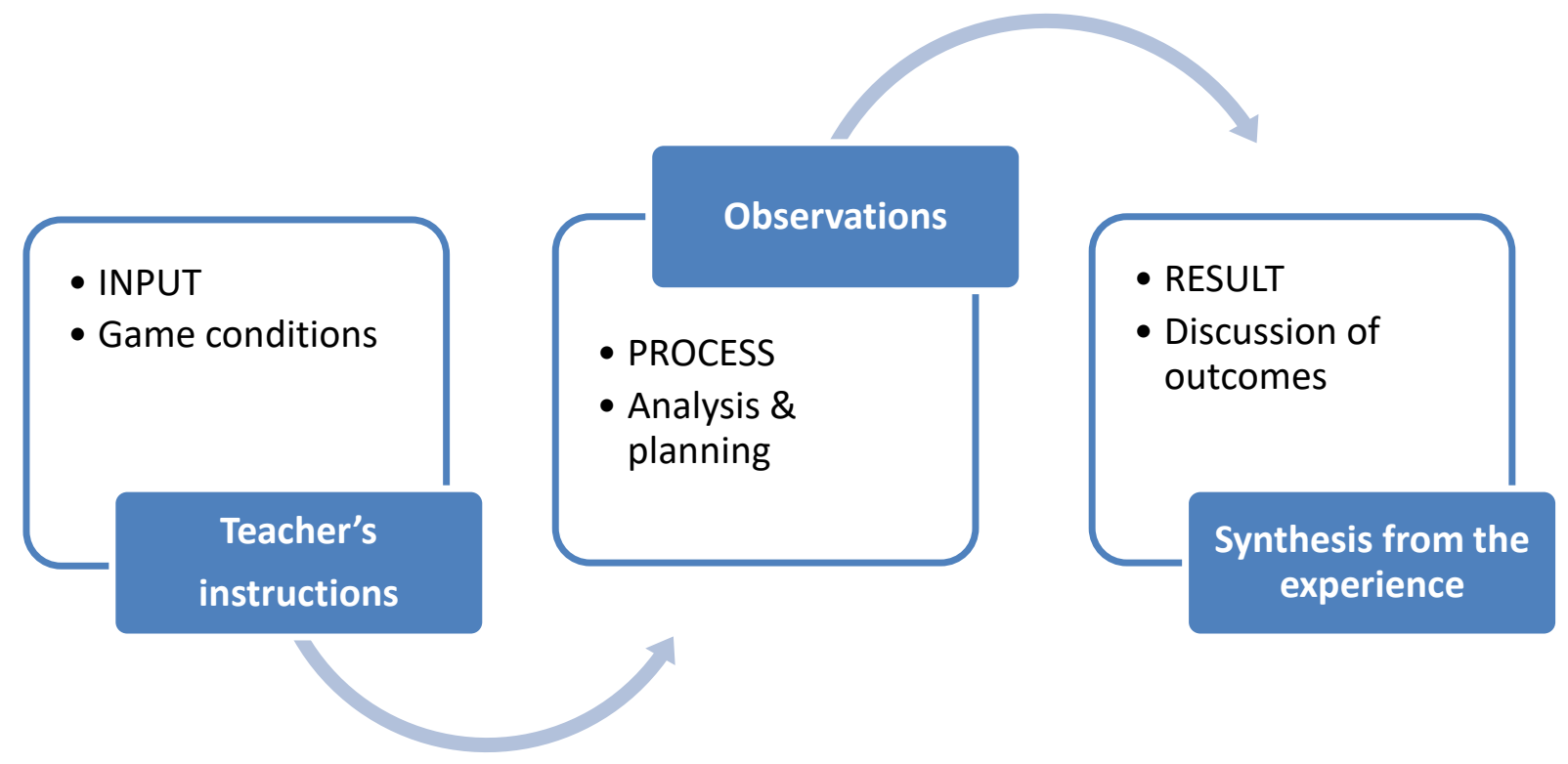

Figure 1. The main stages of the learning process through BSG (compiled by the author)

Entrepreneurship Educators have to be equipped with approved and tested concepts and technical tools to teach experientially. Experiential and Action Learning Pedagogies, Case Method Teaching, Managing Classroom Challenges, Curriculum and Course Design, Use of Technology in the Classroom should be provided too.

Anyone who wants to be educated based on the action will receive the benefits of entrepreneurial education.

No matter what discipline you're from, if you're an academic or an entrepreneur who teaches or has a desire to teach entrepreneurship, you'll leave the program prepared to pass along the benefits of entrepreneurial education. Participants come from all around the world, allowing for a diverse group of peers in the program.

To be able to provide continuous learning process on the base of simulation games universities should recruit and train mentors and coaches. Findings of this study may help teachers in the designing of curriculum that will include BSG and a mechanism of their providing.

\section{Motivation for the BSG}

To be able to counter the competitive labor market, higher educational institutions should include into the teaching process BSG. Students after graduation not always enough to ensure a job. Every employee requires an experience from a young candidate.

It is obvious that getting an experience at universities not an easy task because it is not always possible to study full-time, some of students have work on the side, not all universities can provide and know how to play BSG. According to Crookall (2010a) we would not fly with a pilot who was not thoroughly trained on the simulator before he or she is allowed fly on airplanes.

To be able to provide continuous learning process on the base of simulation games universities should recruit and train mentors and coaches. Findings of this study may help teachers in the designing of curriculum that will include business simulation games and a mekhanizm of their providing.

Aram and Noble (1999) notice that "business schools are not adequately preparing students to understand and cope with the levels of ambiguity and uncertainty they will inevitably face when they take up positions in organizations. They [the authors] believe that this is because the models of teaching and learning that dominate academic practice are those that are appropriate to the stable, predictable aspects of organizational life and do not include the paradoxical and unpredictable characteristics of the professional business environment" (Aram, E. and Noble, D., 1999, as cited in Lainema, 2000, p. 1 of 14).

Copenhagen Business School (CBS) has successful practice, namely introduced BSG into the teaching process on bachelor's and master's degrees. (Löfvall, S., Email communication, June 23, 2011). Despite advantages of BSG, CBS first evaluated its suitability through a successful pre-testing of HotelSim in fall 2010. Test gave a positive 
results. Each university can follow this practice and increase the number of listeners with regard BSG. Students can implement their capstone projects combining theoretical knowledge with simulation games, provide research on a sample group from a higher educational setting and etc.

The important task for the Azerbaijan economy is to promote growth in the nonoil tradable sectors. Azerbaijan's economy has developed around its strong natural resources base, which accounts for over half of gross domestic product (GDP) (figure 2.1) and 90 percent of exports. Although Azerbaijan has experienced rapid oil-driven growth over the last decade, this has not spilled over systematically into other areas of the private sector. Nonoil growth has been dominated by nontradable sectors led by construction, which accounts for about 60 percent of nontradables

\section{Conclusion}

The important task for the Azerbaijan economy is to promote growth in the nonoil tradable sectors. The number of acting small and medium entrepreneurship subjects will grow if they play simulation games without fear of losing their capital. BSG may become a very important tool and make a significant impact for increasing the employment in the labour market and also to the development of SMEs in Azerbaijan. According to Internet World Stats organization the number of the country's Internet users exceeds 7,531 million people or 75,5\% of the total population. Thus we can say that e-educated students will contribute to the the national weith of the country.

\section{Recomendations}

The main recommendations are as follows:

1. Inclusion of BSG into the curricula in the sphere of high education is highly recommended. For this reason, the relevant experience of the world leading universities can foster UNEC and other institutions from Azerbaijan to integrate into the modern education system.

2. BSG will push the game participants to be capable in making own decisions in the future in real conditions, develop an ability to make quick and efficient decisions, track the dynamics of the current and future business trends and predict expected final outputs.

3. Learning by playing, imitation of the real conditions will make students more savvy and in demand in the modern labor market.

4. Using BSG will bring benefits not only the students, but also for teachers of the business schools. As a moderator teachers have the leading role that means that they define the main conditions of the game. Teaching based on gaining empirical experiences through BSG makes the learning process quite interesting and entertaining. Students see a teacher as a trainer, who is ready to help them to reach their goals.

5. The demand for universities that will conduct business simulations will be much higher among applicants, and this is a guarantee of a high rating of the University among educational institutions.

6. Summing up I would like to recall the words of Confucius - "I hear and I forget, I see and I remember, I do and I understand"

\section{References}

[1]. Anderson, P., \& Lawton, L. (2009). Business simulations and cognitive learning: Developments, desires, and future directions. Simulation \& Gaming, 40(2), 193-216.

[2]. Aram, E., \& Noble, D. (1999). Educating prospective managers in the complexity of organizational life. Management Learning, 30(3), p. 1 of 14

[3]. Brown, J. S., Collins, A., \& Duguid, S. (1989). Situated cognition and the culture of learning. Educational Researcher, 18(1), 32-42

[4]. Faria, A. J. (1998). Business simulation games: current usage levels-an update. Simulation \& Gaming, 29(2), 295-308.

[5]. Harley, S. (1993). Situated learning and classroom instruction. Educational Technology, 33(3), 46-51.

[6]. Lainema, T., Makkonen, P., Applying constructivist approach to educational business games: Case REALGAME, DOI: 10.1177/1046878102250601, p. 132

[7]. Löfvall, S., Email communication, June 23, 2011)

[8]. McLellan, H. (1994). Situated learning: Continuing the conversation. Educational Technology, 34(10), 7-8.

[9]. Reiser, B. J. (2004). Scaffolding complex learning: The mechanisms of structuring and problematizing student work. The Journal of the Learning Sciences, 13(3), 273-304. 
[10]. Sorensen, M., (2012), Learnıng with simulation games, Copenghagen Business School p.8,

[11]. Vij S, \& Sharma R. (2018), Experiential Learning through Business Simulation Game in Strategic Management, 6 20th Annual Convention of Strategic Management Forum, "Strategy, Innovation and Entrepreneurship Curriculum in the Era of Disruption", 25-27 December 2018, Indian Institute of Management Tiruchirapalli ( IIM Trichy) p 3-5

[12]. Walters, B. A., Coalter, T. M., \& Rasheed, A. M. (1997). Simulation games in business policy courses: Is there value for students? Journal of Education for Business, 72(3), 170-174.

[13]. Avramenko, A. (2012). Enhancing students' employability through business simulation. Education+ Training, 54(5), 355- 367

[14]. OECD Learning Compass 2030, http://www.oecd.org/education/2030-project/teaching-andlearning/learning/learning-compass-2030/OECD_Learning_Compass_2030_concept_note.pdf

[15]. https://www.internetworldstats.com

[16]. https://www.marketplace-simulation.com/strategy-business-policy-demo 